\title{
Reduced Graphene Oxide/Gold Nanoparticles Modified Screen- Printed Electrode for the Determination of Palmitic Acid
}

\author{
Chin Boon Ching, ${ }^{1}$ Jaafar Abdullah $\mathbb{D}^{1,2}$ and Nor Azah Yusof ${ }^{1,2}$ \\ ${ }^{1}$ Department of Chemistry, Faculty of Science, Universiti Putra Malaysia, 43400 UPM Serdang, Selangor, Malaysia \\ ${ }^{2}$ Institute of Advanced Technology, University Putra Malaysia, 43400 Serdang, Selangor, Malaysia \\ Correspondence should be addressed to Jaafar Abdullah; jafar@upm.edu.my
}

Received 9 October 2020; Revised 12 December 2020; Accepted 1 April 2021; Published 14 April 2021

Academic Editor: Domenico Caputo

Copyright (C) 2021 Chin Boon Ching et al. This is an open access article distributed under the Creative Commons Attribution License, which permits unrestricted use, distribution, and reproduction in any medium, provided the original work is properly cited.

\begin{abstract}
Palm oil is one of the major oils and fats produced in the world today. The quality of palm oil is crucial to be investigated, and one of the quality indices is free fatty acid (FFA) content. Therefore, in this study, an electrochemical approach for the determination of FFA has been explored as an alternative to replace the conventional method (titration method). The electrochemical method was developed based on electrochemically reduced graphene oxide ( $\mathrm{rGO}$ ) coupled with gold nanoparticles (AuNPs) deposited onto a screen-printed carbon electrode (SPCE) via drop-casting technique. The voltammetric behaviour of 2-methyl-1,4naphthoquinone $\left(\mathrm{VK}_{3}\right)$ in the presence of palmitic acid at the modified electrode was investigated in an acetonitrile/water mixture containing lithium perchlorate $\left(\mathrm{LiClO}_{4}\right)$. The electrochemical detection of palmitic acid was based on the voltammetric reduction of $\mathrm{VK}_{3}$ to form the corresponding hydroquinone which is proportional to the concentration of palmitic acid. Under optimum conditions, the developed method showed a good linear relationship towards palmitic acid in the concentration ranging from $0.192 \mathrm{mM}$ to $0.833 \mathrm{mM}$ with the detection limit of $0.015 \mathrm{mM}$. The exploration of the developed system is expected to achieve high sensitivity and excellent selectivity towards the determination of FFA content in palm oil.
\end{abstract}

\section{Introduction}

The palm oil (Elaeis guineensis) originated in the tropical rain forest of Western Equatorial Africa and leads to an astonishing increase of plantation size throughout Southeast Asia [1]. 19.52 million tonnes of crude palm oil have been produced in Malaysia, making Malaysia the world second-largest producer of palm oil in the world [2]. Determination of free fatty acids (FFA) in palm oil is the main issue focused by many researchers nowadays because FFA content will affect the quality and marketing of palm oil products. The common factors which may cause an increase in FFA content are damaged palm fruits during harvesting and poor storage methods. Besides, crude palm oil itself naturally releases free fatty acids and the reaction can be increased by the microbial lipase enzyme. High FFA content will lead to many problems such as low product yield, unpleasant flavour, and complications in sample processing procedures which subsequently influence the commercial value of palm oil in industry. Stan- dard determination for the FFA content (as palmitic acid) has been set by the Malaysian Palm Oil Board (MPOB), which its composition in crude palm oil (CPO) and refined bleached deodorized oil (RBDO) should be less than $5 \%$ and $0.1 \%$, respectively [3].

Graphene, a two-dimensional material with a planar sheet of $\mathrm{sp}^{2}$-bonded carbon atoms in a hexagonal structure, has widely been utilized in many sensor fields due to its unique and interesting properties, such as high surface area, good chemical stability, high mechanical strength, and excellent conductivity [4]. After undergoing an oxidation process to produce graphene oxide (GO), oxygen functional groups such as hydroxyl, epoxy, and carbonyl functional groups attach on the GO surface [5]. The presence of these functional groups on the graphene framework aids in interacting with an analyte such as acid for an effective detection process. However, the initially perfect $\pi$-conjugated system in graphite will be disrupted by these oxygen functional groups which then breaks the long-conjugated network of the graphitic 
lattice, resulting in the decrease of electron transfer mobility and electron scattering, thus lowers the conductivity of graphene oxide [6]. Some of the oxygen functional groups need to be removed to overcome the problem caused by the oxidation process. In this study, electrochemical reduction has been proposed to reduce GO, because this method is simple, nontoxic, time-saving, less expensive, and green in nature compared to other traditional methods such as thermal reduction and chemical reduction [7]. The deposited GO on SPCE was electrochemically reduced to reduced graphene oxide ( $\mathrm{rGO}$ ) by cyclic voltammetry $(\mathrm{CV})$ to eliminate oxygen functionality and hence restore the electrical properties of graphene [8]. In addition, the development of nanocomposite materials based on the integration of graphene with some semiconductor or conductor nanomaterials such as gold nanoparticles was studied to further improve the sensitivity of the electrochemical sensors [9]. The electrocatalytic activity of gold is proved to be further enhanced when supported on graphene or its derivatives, owing to the synergic effect between these two components. In addition, gold nanoparticles (AuNPs) have shown magnificent properties such as great surface area, small dimensional size, and good electronic properties, suitable to be used in sensor applications [10].

On the other hand, quinone-hydroquinone redox couples are unique compounds and are studied intensely by researchers due to the electrochemical behaviour of quinone, associated with its electron-proton transfer equilibrium and kinetics [11]. In detail, the electrochemical behaviour of quinones is sensitive to the presence of hydrogen ions which are then involved in the proton transfer reaction. Protons released from acid are accepted easily by quinone to from hydroquinone and subsequently generate a peak which has a good correlation with the concentration of acid; hence, the determination of the concentration of palmitic acids can be determined [12]. In neutral aprotic solvents such as acetonitrile $(\mathrm{AN})$, semiquinone $\left(\mathrm{Q}^{--}\right)$and quinone dianion $\left(\mathrm{Q}^{2-}\right)$ can be produced from quinones $(\mathrm{Q})$ after two successive one-electron reduction steps, generating two distinct cathodic peaks. The first electron transfer step, Q to $\mathrm{Q}^{--}$, exhibits a clearly defined reversible voltammetric signal, whereas the second electron transfer, $\mathrm{Q}$ to $\mathrm{Q}^{2-}$, is generally related to quasireversible signal. The behaviour of the second electron transfer is reported to be more sensitive to the interaction between the materials deposited and the surface of the electrode depending on the concentration of proton donors and cationic species capable of ion pairing. When the acid is added, hydroquinone $\mathrm{QH}_{2}$ is formed and subsequently a peak formation will be observed. In short, the sequence of the reaction of quinones can be explained as two-electron transfer coupled with two-proton acceptance process, suitable to be used in the determination of acid [13].

Usually, the traditional way for the determination of free fatty acids in palm oil is through the acid-base titration method by titration sample against potassium hydroxide in hot 2-propanol solution, and phenolphthalein is used as an indicator [14]. Although this method is direct and easy, it is encountered with some problems such as time-consuming, labour-intensive, and lack of accuracy [15]. Moreover, during the neutralization process, some samples contain coloured substances, mainly carotenoids, which causes difficulty to detect a subtle colour change of the indicator in the transition range, thus leading to the inaccurate result [16]. In this study, an electrochemical method based on screen-printed carbon electrode (SPCE) modified reduced graphene oxide coupled with gold nanoparticles for the determination of FFA content in palm oil has been proposed. The principle of the determination is based on the electrochemical reduction of $\mathrm{VK}_{3}$ in an acetonitrile/water mixture containing lithium perchlorate $\left(\mathrm{LiClO}_{4}\right)$ corresponding to concentrations of FFA.

\section{Experimental}

2.1. Chemicals and Instruments. All chemicals were of analytical grade. Graphene oxide was purchased from GO Advanced Solutions Sdn. Bhd (Malaysia). Gold chloroauric acid salt $\left(\mathrm{HAuCl}_{4} \cdot 4 \mathrm{H}_{2} \mathrm{O}\right)$, potassium ferrocyanide $\left(\mathrm{K}_{3} \mathrm{Fe}\right.$ $\left.(\mathrm{CN})_{6}\right)$, potassium chloride $(\mathrm{KCl}), 2$-methyl-1,4-naphthoquinone $\left(\mathrm{VK}_{3}\right)$, lithium perchlorate $\left(\mathrm{LiClO}_{4}\right)$, phenolphthalein, and phosphate buffer saline solution with a $\mathrm{pH}$ of 7.4 (PBS) were purchased from Sigma-Aldrich (USA). Palmitic acid $\left(\mathrm{C}_{16} \mathrm{H}_{32} \mathrm{O}_{2}\right), 98 \%$, was purchased from Acros Organics (USA). Potassium hydroxide (KOH), 2-propanol, and acetonitrile were purchased from R\&M Chemicals (United Kingdom). Deionized water $\left(18.2 \mathrm{~m} \Omega \cdot \mathrm{cm}\right.$ at $25^{\circ} \mathrm{C}$, Milli-Q) was used throughout the experiments. The screen-printed carbon electrode (SPCE) consists of carbon-based working and counter electrodes, and a silver/silver chloride (Ag/AgCl) reference electrode was purchased from Rapid Labs Sdn Bhd (Malaysia).

Electrochemical measurements were done using an Autolab Instrument Model Autolab Type III (Eco Chemie B. V., Netherlands). Cyclic voltammetry (CV), linear sweep voltammetry (LSV), and electrochemical impedance spectroscopy (EIS) data analyses were carried out using Nova 1.11 software. Fourier transform infrared (FTIR) spectra were analysed using a Thermo Nicolet 6700 FT-IR spectrometer (USA) in the range of 4000 to $400 \mathrm{~cm}^{-1}$. Field Emission Scanning Electron Microscopy (FESEM) coupled with Energy Dispersive X-ray (EDX) images was obtained using a Nova Nanosem 230, FEI (USA) instrument, and Raman spectra were obtained using a Witec instrument model Alpha 300R (Germany).

\subsection{Preparation of Stock Solution}

2.2.1. Preparation of Working Solution. For the preparation of working solution, 2-methyl-1,4-naphthoquinone $\left(\mathrm{VK}_{3}\right)$ was dissolved in water/acetonitrile mixture solvent containing lithium perchlorate $\left(\mathrm{LiClO}_{4}\right)$. For $\mathrm{VK}_{3}$ concentration, the range of $2 \mathrm{mM}$ to $6 \mathrm{mM}$ of $\mathrm{VK}_{3}$ was prepared. For $\mathrm{LiClO}_{4}$ concentration, the range of $1.5 \mathrm{M}$ to $4.0 \mathrm{M}$ of $\mathrm{LiClO}_{4}$ was prepared. Both $\mathrm{VK}_{3}$ and $\mathrm{LiClO}_{4}$ were dissolved in mixture solvent of water and acetonitrile. For the ratios of the mixture solvent, 3 ratios were prepared, which were $1: 1,1: 3$, and $3: 1$ of water to acetonitrile ratios. The optimization study was carried out using cyclic voltammetry (CV). 
2.2.2. Preparation of Palmitic Acid Solution. $5 \mathrm{mM}$ of stock solution was prepared by dissolving $12.8 \mathrm{mg}$ palmitic acid in $10 \mathrm{~mL}$ acetonitrile. Different concentrations of palmitic acid ranged from $0.192 \mathrm{mM}$ to $0.833 \mathrm{mM}$ were studied by spiking a known amount of palmitic acid solution into the working solution prepared above. The performance study of the electrode towards palmitic acid was carried out using linear sweep voltammetry (LSV).

\subsubsection{Preparation of Cooking Oil Stock Samples. Sample} preparation for correlation study was carried out based on the reported methods [17], with slight alteration. Cooking oil (Buruh, Lam Soon Edible Oils Sdn. Bhd.) was used as a real sample in this study. A stock oil solution of $0.5 \mathrm{~g} / \mathrm{mL}$ was prepared by dissolving $5 \mathrm{~g}$ of cooking oil in $10 \mathrm{~mL} \mathrm{2-}$ propanol. This solution was sonicated for 10 minutes until homogenous mixture was obtained. This sample was then used to prepare stock solution and stock palmitic acid solutions.

2.2.4. Preparation of Stock Palmitic Acid Solution. $0.1 \mathrm{~g} / \mathrm{mL}$ stock solution of palmitic acid was prepared by dissolving $0.5 \mathrm{~g}$ palmitic acid in $5 \mathrm{~mL}$ of the stock oil solution as prepared above. The solution was sonicated for 10 minutes at room temperature until homogeneous solution was obtained.

For real sample analysis, the prepared stock oil solution was spiked with palmitic acid to the desired concentrations in the range from 1 a.d. to 40 a.d.

\subsection{Preparation of Reduced Graphene Oxide/Gold} Nanoparticle-Modified SPCE. $2.5 \mathrm{mg} / \mathrm{mL}$ graphene oxide (GO) solution was diluted using $0.1 \mathrm{M}$ phosphate buffer solution $(\mathrm{pH}$ 7.4) and ultrasonicated for 2 hours to obtain a homogeneous of $1.0 \mathrm{mg} / \mathrm{mL}$ GO suspension. After that, $5 \mu \mathrm{L}$ of the as-prepared solution was drop cast on the surface of SPCE and it was allowed to dry at room temperature. Subsequently, SPCE was electrochemically reduced using cyclic voltammetry $(\mathrm{CV})$ in the potential range of $0 \mathrm{~V}$ to $-1.5 \mathrm{~V}$ with a scan rate of $100 \mathrm{mV} / \mathrm{s}$ in a $0.1 \mathrm{M} \mathrm{KCl}$ solution for 15 cycles. The rGO-modified SPCE was then washed carefully with distilled water and dried at room temperature. After the rGOmodified SPCE was dried, $10 \mu \mathrm{L}$ of $1.5 \mathrm{mM}$ gold nanoparticles was drop cast on the surface of SPCE and it was let to dry overnight.

The prepared $\mathrm{rGO} / \mathrm{AuNP}$-modified SPCE was characterized using FESEM and EDX for morphological and elemental analysis. FTIR was used to analyse the functional groups present on graphene oxide, reduced graphene oxide, and reduced graphene oxide/gold nanoparticle composites. Raman spectroscopy was used to reveal the detailed structural information of graphene materials.

2.4. Electrochemical Study of Reduced Graphene Oxide/Gold Nanoparticle-Modified SPCE. The electrochemical behaviour of rGO/AuNP-modified SPCE was investigated by cyclic voltammetry $(\mathrm{CV})$ in $0.005 \mathrm{M} \mathrm{K}_{3} \mathrm{Fe}(\mathrm{CN})_{6} / 0.1 \mathrm{M} \mathrm{KCl}$ solution. Optimization parameter for the fabrication process of the modified electrode such as rGO concentration, $\mathrm{rGO}$ volume, and AuNP concentration was also studied.
Scan rate study of the modified electrodes was performed by $\mathrm{CV}$ in $0.005 \mathrm{M} \mathrm{K}_{3} \mathrm{Fe}(\mathrm{CN})_{6} / 0.1 \mathrm{M} \mathrm{KCl}$ solution by varying the scan rate from $10 \mathrm{mV} / \mathrm{s}$ to $100 \mathrm{mV} / \mathrm{s}$. Electrochemical impedance spectroscopy (EIS) of the modified electrodes was carried out using $\mathrm{CV}$ with a frequency range from $100 \mathrm{kHz}$ to $0.1 \mathrm{~Hz}$ and applied potential of $225 \mathrm{mV}$ with AC voltage amplitude of $0.01 \mathrm{~V}$.

2.5. Analytical Performance of the Reduced Graphene Oxide/Gold Nanoparticle-Modified SPCE towards Working Solution. The electrochemical behaviour of $\mathrm{rGO}$ and rGO/AuNP-modified SPCE towards 2-methyl-1,4-naphthoquinone $\left(\mathrm{VK}_{3}\right)$ in acetonitrile/water mixture containing lithium perchlorate was evaluated using cyclic voltammetry (CV). In order to obtain the maximum response of the modified electrode, the optimization of $\mathrm{VK}_{3}$ concentrations, $\mathrm{LiClO}_{4}$ concentrations, and the ratios of the solvent mixture was studied.

Investigation of $\mathrm{rGO}$ and $\mathrm{rGO} / \mathrm{AuNP}$-modified SPCE towards palmitic acid detection using the optimized working solution was also evaluated using linear sweep voltammetry (LSV) scanning from $1.5 \mathrm{~V}$ to $-1.5 \mathrm{~V}$ at a scan rate of $50 \mathrm{mV} / \mathrm{s}$. Different concentrations of palmitic acid including $0.192 \mathrm{mM}, 0.370 \mathrm{mM}, 0.536 \mathrm{mM}, 0.690 \mathrm{mM}$, and $0.833 \mathrm{mM}$ were tested. The current response of $\mathrm{rGO}$ and $\mathrm{rGO} / \mathrm{AuNP}$ modified SPCE was obtained by injected different volumes of palmitic acid into the prepared working solution.

2.6. Applicability of the Reduced Graphene Oxide/Gold Nanoparticle-Modified SPCE towards Spiked Real Sample Analysis. Investigation of $\mathrm{rGO} / \mathrm{AuNP}$-modified SPCE towards real sample spiked with known concentration of palmitic acid of 1 a.d., 10 a.d., 20 a.d., 30 a.d., and 40 a.d. was evaluated using linear sweep voltammetry (LSV) at the scan range of $1.5 \mathrm{~V}$ to $-1.5 \mathrm{~V}$ with a scan rate of $50 \mathrm{mV} / \mathrm{s}$.

2.7. Validation of the Developed Method with the Standard Titrimetric Method Using Spiked Real Sample. In order to evaluate the potential application of the developed system in real sample analysis, a validation study of the developed method towards the standard method (MPOB standard titrimetric method) for analysis of free fatty acids (palmitic acid) was investigated. Different palmitic acid concentrations of 5 a.d., 15 a.d., and 35 a.d. were used.

For the standard method, the mixture of cooking oil $(1 \mathrm{~g})$, palmitic acid with known concentration $(10 \mathrm{~mL})$, 2propanol $(50 \mathrm{~mL})$, and phenolphthalein $(0.5 \mathrm{~mL})$ as indicator was put into an Erlenmeyer flask. The flask was then placed on a hot plate, and the temperature was adjusted to about $40^{\circ} \mathrm{C}$. The flask consisting of the mixture was shaken gently and continuously titrated against standard $\mathrm{KOH}$ $(0.1 \mathrm{M})$ until the first permanent pink colour appears. The first permanent pink colour change must persist for $30 \mathrm{~s}$. The volume of $\mathrm{KOH}$ needed to neutralise the acid was recorded. The concentration of palmitic acid (\% FFA) can be calculated from

$$
\% \text { FFA }(\text { Palmitic acid })=\frac{(v-b) \times N \times 25.6}{w},
$$




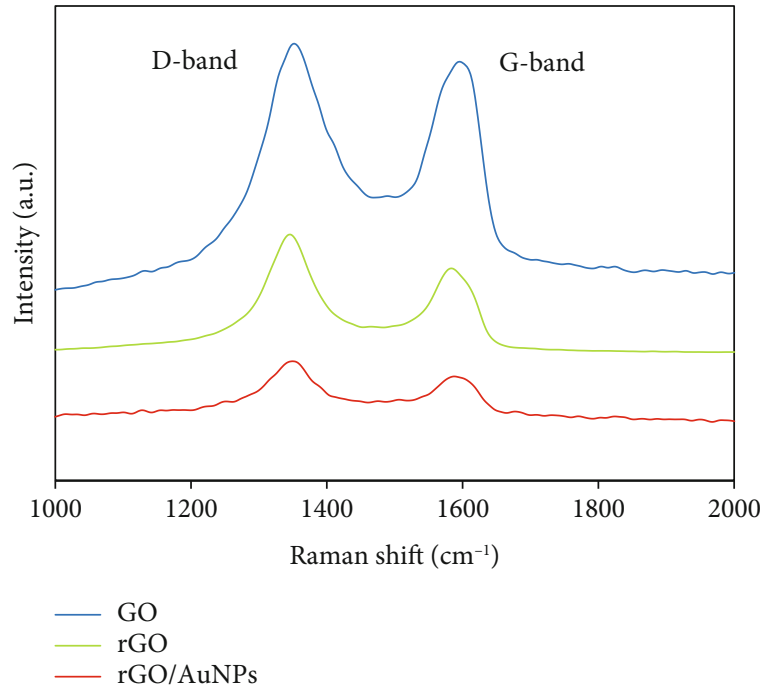

(a)

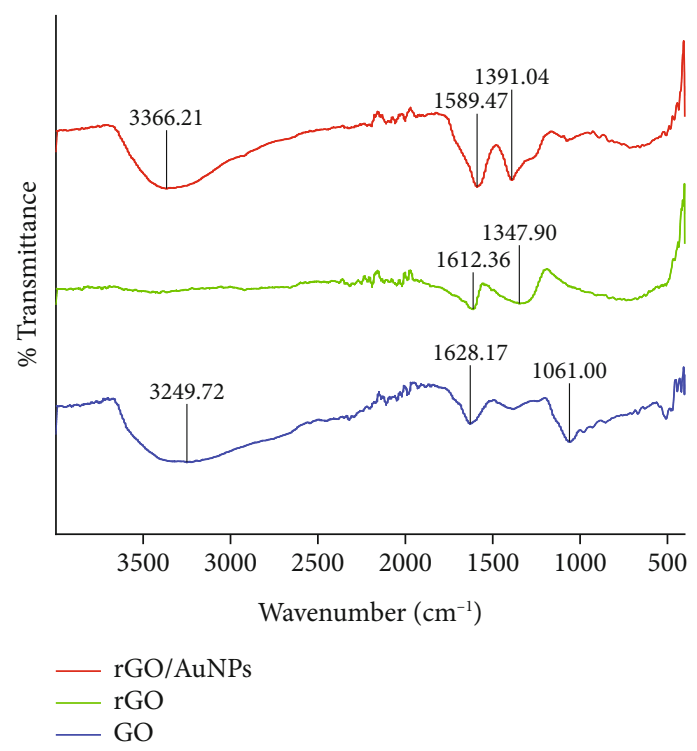

(b)

FIGURe 1: (a) Raman spectra of GO, rGO, and rGO/AuNP-modified SPCE and (b) FTIR spectra of GO, rGO, and rGO/AuNP-modified SPCE.

where $v$ is the volume in $\mathrm{mL}$ of titration solution, $b$ is the volume in mL of the blank, $N$ is the normality of the standard $\mathrm{KOH}$ solution, and $w$ is the weight of the sample of oil in grams.

\section{Results and Discussion}

3.1. Characterization of the Modified SPCE. Raman spectroscopy is a nondestructive spectroscopic technique that is immensely used to provide the detailed structural information of carbon materials, particularly graphene materials [18]. From Figure 1(a), Raman spectra of the GO, rGO, and rGO/AuNP samples exhibit two obvious signals with their peaks located at approximately $1320-1360 \mathrm{~cm}^{-1}$ and 1570 $1600 \mathrm{~cm}^{-1}$, which corresponds to the $\mathrm{D}$ and $\mathrm{G}$ bands, respectively. All Raman spectra depicted the same pattern of the curve, which implies that the structure of graphene was not affected when the reduction process of GO to $\mathrm{rGO}$ and the addition of AuNPs onto rGO sheets take place. The ratio between the $\mathrm{D}$ and $\mathrm{G}$ bands $\left(I_{\mathrm{D}} / I_{\mathrm{G}}\right)$ can be calculated and used to estimate the extent of structural disorder [19]. $I_{\mathrm{D}} / I_{\mathrm{G}}$ intensity for $\mathrm{rGO}(1.16)>\mathrm{GO}$ (1.04), indicating GO is successfully reduced to rGO. In another word, a decrease in the average size of in-plane $\mathrm{sp}^{2}$ domains due to the removal of the oxygen functional groups in the rGO has occurred, proving the successful reduction which restores the $\mathrm{sp}^{2}$ domains of graphene [20]. Meanwhile, for the Raman spectrum of $\mathrm{rGO} / \mathrm{AuNP}$ nanocomposite material, the calculated $I_{\mathrm{D}} / I_{\mathrm{G}}$ intensity is 1.06 , which is lower than rGO after the binding with AuNPs. The decrease in the $I_{\mathrm{D}} / I_{\mathrm{G}}$ intensity was because of the aggregation of AuNPs on the rGO matrix and subsequently caused an increase in the number of graphitic domains. The interaction of rGO and AuNPs affects the lattice constant and electronic properties of the materials [21].
FTIR was used to detect the functional groups and characterize the molecule structure change of the materials of the modified electrode. From Figure 1(b), FTIR spectra of GO showed absorption peaks at $1061 \mathrm{~cm}^{-1}, 1628 \mathrm{~cm}^{-1}$, and $3250 \mathrm{~cm}^{-1}$ which are attributed to $\mathrm{C}-\mathrm{O}-\mathrm{C}, \mathrm{C}=\mathrm{C}$, and $\mathrm{O}-\mathrm{H}$ stretching vibrations, respectively [22]. After the reduction of $\mathrm{GO}$, the $\mathrm{C}-\mathrm{O}-\mathrm{C}$ and $\mathrm{O}-\mathrm{H}$ stretching vibrations of $\mathrm{GO}$ disappeared, proving that the reduction of $\mathrm{GO}$ to $\mathrm{rGO}$ was successful. Ring strains present in $\mathrm{C}-\mathrm{O}-\mathrm{C}$ bonding configurations of $\mathrm{GO}$ are more susceptible to ring-opening reactions, which lead to $\mathrm{sp}^{2}$ carbon $(\mathrm{C}=\mathrm{C})$ upon the reduction process. In addition, a strong $\mathrm{C}=\mathrm{C}$ stretching peak at $1612 \mathrm{~cm}^{-1}$ and $-\mathrm{CH}_{3}$ bending peak at $1348 \mathrm{~cm}^{-1}$ were observed in FTIR spectra of rGO, suggesting the restoration of the carbon basal plane in rGO after reduction. Moreover, FTIR spectra for $\mathrm{rGO} / \mathrm{AuNPs}$ depicted the characteristic bands of citrate at 3366,1589 , and $1391 \mathrm{~cm}^{-1}$. The presence of the signal at $3366 \mathrm{~cm}^{-1}$ was indicative of the stretching vibration of the $-\mathrm{OH}$ group, and the band at $1589 \mathrm{~cm}^{-1}$ was assigned to the $\mathrm{C}=\mathrm{O}$ stretching of carboxylate ions of citrate, which implied that the hydroxyl group and the carboxyl group contained in the sodium citrate formed strong hydrogen bonds with the residual oxygen functionalities on the rGO surfaces. Moreover, the peak at $1391 \mathrm{~cm}^{-1}$ indicated the intensity of $\mathrm{C}-\mathrm{OH}$ deformation vibration, which likely arose from surface-bound sodium citrate. In short, the results showed that the sodium citrate moieties are attached to the surface of rGO and act as a capping agent which stabilizes the rGO [23].

The surface morphology of GO, rGO, and rGO/AuNPmodified SPCE was characterized using FESEM with $100 \mathrm{~K}$ magnification. As shown in Figures 2(a) and 2(b), it was noted that both GO and rGO film were successfully deposited onto the electrode surface with a typical crumpled and wrinkled multilayer sheet structure. A larger surface area 

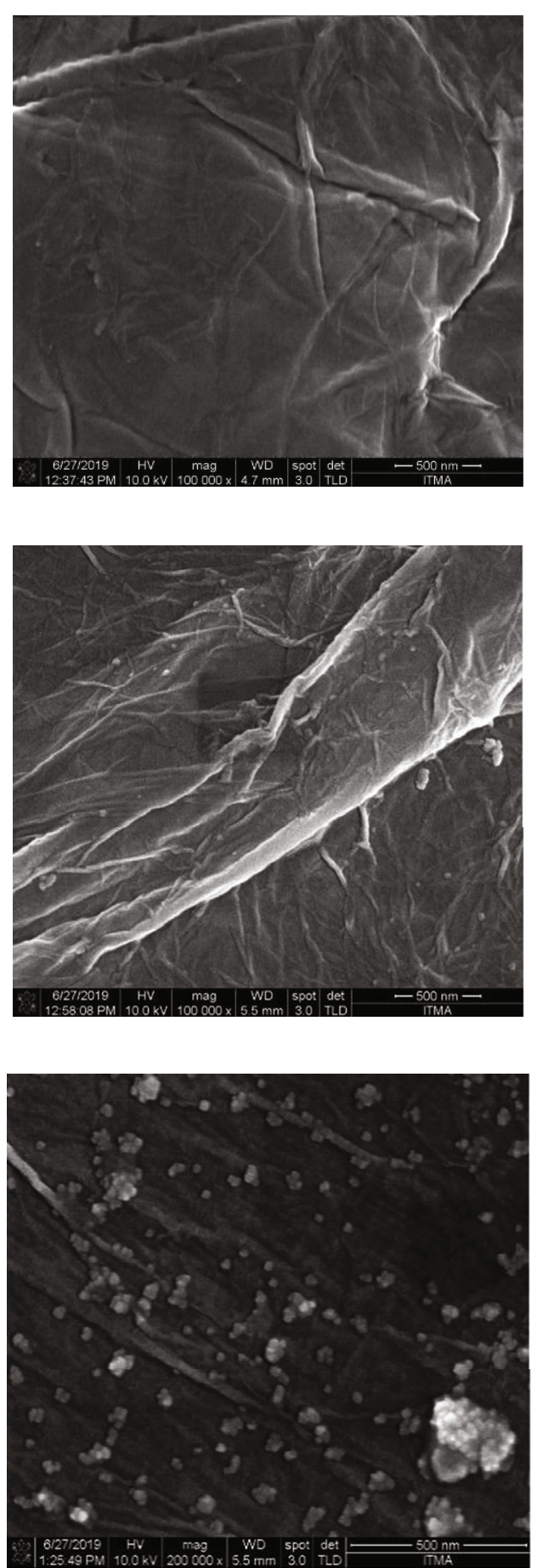

Figure 2: FESEM and EDX images of (a) GO, (b) rGO, and (c) rGO/AuNP-modified SPCE.

can be provided for the interaction with the analytes due to these wrinkled and edge nanostructures of rGO sheets [24]. Moreover, the presence of carbon $(\mathrm{C})$ and oxygen $(\mathrm{O})$ in both $\mathrm{GO}$ and rGO films could also be proven by the EDX image. In $\mathrm{GO}$, it consisted of $36.3 \%$ of C element, $32.1 \%$ of O element, and other trace elements which involved during the preparation process of GO involving the use of PBS solution. In rGO, it consisted of $89.3 \%$ of $\mathrm{C}$ element and $8.8 \%$ of $\mathrm{O}$ ele- ment. Thus, the signal of $\mathrm{O}$ is significantly decreased in $\mathrm{rGO}$ from $32.1 \%$ to $8.8 \%$, indicating that GO is successfully reduced to rGO. This is because mainly the oxygen groups such as epoxy and hydroxyl groups present in GO are removed after the electrochemical reduction occurs. However, the reduction process cannot remove all oxygen functional groups because these functional groups left behind will be involved in the reaction with other elements such as 


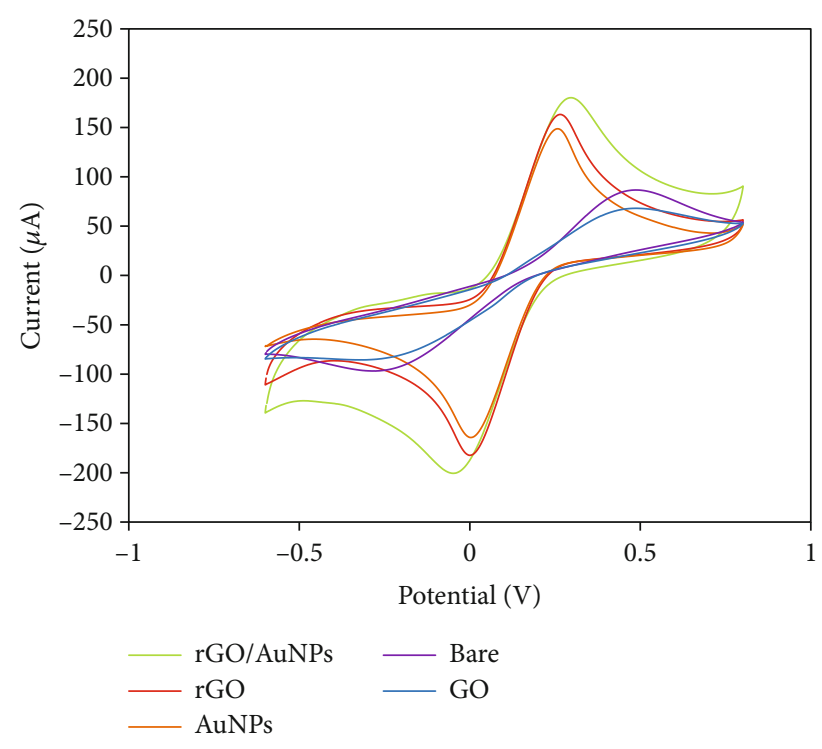

FIGURE 3: Cyclic voltammograms of different types of SPCE in $0.1 \mathrm{M}$ $\mathrm{KCl}$ solution containing $5.0 \mathrm{mM}\left[\mathrm{Fe}(\mathrm{CN})_{6}\right]^{3-/ 4-}$ solution at a scan rate of $100 \mathrm{mV} / \mathrm{s}$.

AuNPs, as verified by the presence of $8.8 \%$ of $\mathrm{O}$ element in rGO from EDX spectra.

Based on Figure 2(c), a large amount of AuNPs is densely and uniformly dispersed on the surface of rGO film with little coagulation. EDX spectrum of the rGO-AuNP nanocomposites also showed the presence of all $\mathrm{C}, \mathrm{O}$, and Au signals, consisting of $65.8 \% \mathrm{C}$ element, $4.7 \% \mathrm{O}$ elements, and $29.5 \% \mathrm{Au}$ element. These results distinctly confirmed the formation of rGO/AuNP nanocomposites on SPCE. The oxygen functional groups left behind in rGO could interact with AuNPs along the graphene surface through electrostatic interaction, forming $\mathrm{rGO} / \mathrm{AuNP}$ nanocomposite materials [25]. Therefore, based on the proposed method, rGO/AuNP nanocomposite was successfully prepared and it is proved to be a reliable preparation method.

\subsection{Electrochemical Characterization of the Modified SPCE}

3.2.1. Electrochemical Study of the Modified SPCE. The electrochemical behaviours of bare GO, AuNPs, rGO, and rGO/AuNP-modified SPCE were characterized using cyclic voltammetry $(\mathrm{CV})$ in $0.005 \mathrm{M} \mathrm{K}_{3}\left[\mathrm{Fe}\left(\mathrm{CN}_{6}\right)\right]$ containing $0.1 \mathrm{M} \mathrm{KCl}$ at a scan rate of $100 \mathrm{mV} / \mathrm{s}$ in the potential range of $-0.6 \mathrm{~V}$ to $0.8 \mathrm{~V}$. Figure 3 depicts the voltammogram of bare, $\mathrm{GO}$, AuNPs, rGO, and rGO/AuNP-modified SPCE, respectively. Bare SPCE gave a clearly defined reversible electrochemical response. After modification with GO, a decrease in peak current has occurred, due to the poor conductivity of the GO which behaved as an electrical insulator because of the presence of polar and negatively charged functional groups such as $-\mathrm{COOH},-\mathrm{COOR}$ on the $\mathrm{rGO}$ surface. These negatively charged functional groups can ionize in solution easily and subsequently generate a repulsive force over the negatively charged $\left[\mathrm{Fe}(\mathrm{CN})_{6}\right]^{3-}$ ions, which result in the difficulty for the electron transfer between the surface of the electrode and the electrolyte (ions) to occur [26].
In addition, the rGO-modified SPCE had the secondhighest peak current with a smaller peak-to-peak separation $\left(\Delta E_{\mathrm{p}}\right)$ compared with bare and GO-modified electrodes, indicating that the excellent conductivity and great surface area of rGO could help to speed up the whole electrochemical process. This is because of the removal of the negative charge functional groups in the GO sheet after the reduction process, leading to the absence of repulsive force which accelerates the electron transfer between the electrode surface and the redox species. This phenomenon was also attributed to the significant improvement of the electrical conductivity of the rGO film, presumably owing to the restoration of a graphitic network of $\mathrm{sp}^{2}$ bonds [26].

After the addition of AuNPs into the rGO sheet to form rGO/AuNP composites, the resulting modified SPCE was higher than the rGO-modified SPCE. The increase in the peak current of rGO/AuNP-modified SPCE confirmed the contribution from the nanocomposites. AuNP-modified SPCE only showed the third in conductivity among all electrodes. AuNPs need to be added and combined with rGO sheets to enhance the current response because AuNPs act as an electron transfer channel, which can further improve the conductivity of the rGO film. As a consequence, the charge transfer process between the modified layer and electrolyte (ions) was accelerated and occurred more efficiently [27]. On top of that, the electrochemical behaviour of the composite-modified electrode improved highest compared with a single ingredient modified electrode (rGO-modified SPCE or AuNP-modified SPCE) due to the synergic effect of both graphene and gold nanoparticles which showed a good electrical conductivity and large electroactive surface area [28]. It can be summarized that the redox signal of the modified electrode follows the order of $\mathrm{rGO} / \mathrm{AuNPs}>\mathrm{rGO}$ $>$ AuNPs $>$ bare $>$ GO.

For the scan rate study of different electrodes, from Figures 4(a)-4(c), the anodic peak shifted positively while the cathodic peak shifted negatively, generating slightly larger $\Delta E_{\mathrm{p}}$ with increasing scan rates from $10 \mathrm{mV} / \mathrm{s}$ to $100 \mathrm{mV} / \mathrm{s}$. The linear graph of the anodic and cathodic peak current $\left(I_{\mathrm{p}}\right)$ versus the square root of the scan rate $\left(v^{1 / 2}\right)$ was plotted for all modified electrodes, and good linearity was obtained, suggesting that all undergo diffusion-controlled process [29]. The kinetics of a diffusion-controlled system is defined as the diffusion of ferrocyanide ions from the solution into the interface of the electrode due to a concentration gradient when ions are involved in redox reaction. By using Randles-Sevcik equation:

$$
I_{\text {peak }}=\left(2.69 \times 10^{5}\right) n^{2 / 3} \mathrm{ACD}^{1 / 2} V^{1 / 2} \text {, }
$$

where $I_{\text {peak }}$ refers to the anodic peak current, $n$ is the total number of transferring electrons in redox reaction, $A$ is the microscopic surface area of the electrode, $D$ is the diffusion coefficient of ferrocyanate, and $C$ is the concentration of $\mathrm{K}_{3} \mathrm{Fe}(\mathrm{CN})_{6}$. Assuming $n=1$ and $D=7.6 \times 10^{-6} \mathrm{~cm}^{2} \mathrm{~s}^{-1}$, the effective surface areas for bare SPCE, rGO-modified SPCE, and $\mathrm{rGO} / \mathrm{AuNP}$-modified SPCE were $0.061 \mathrm{~cm}^{2}, 0.127 \mathrm{~cm}^{2}$, and $0.130 \mathrm{~cm}^{2}$, respectively. The results indicate that $\mathrm{rGO}$ 

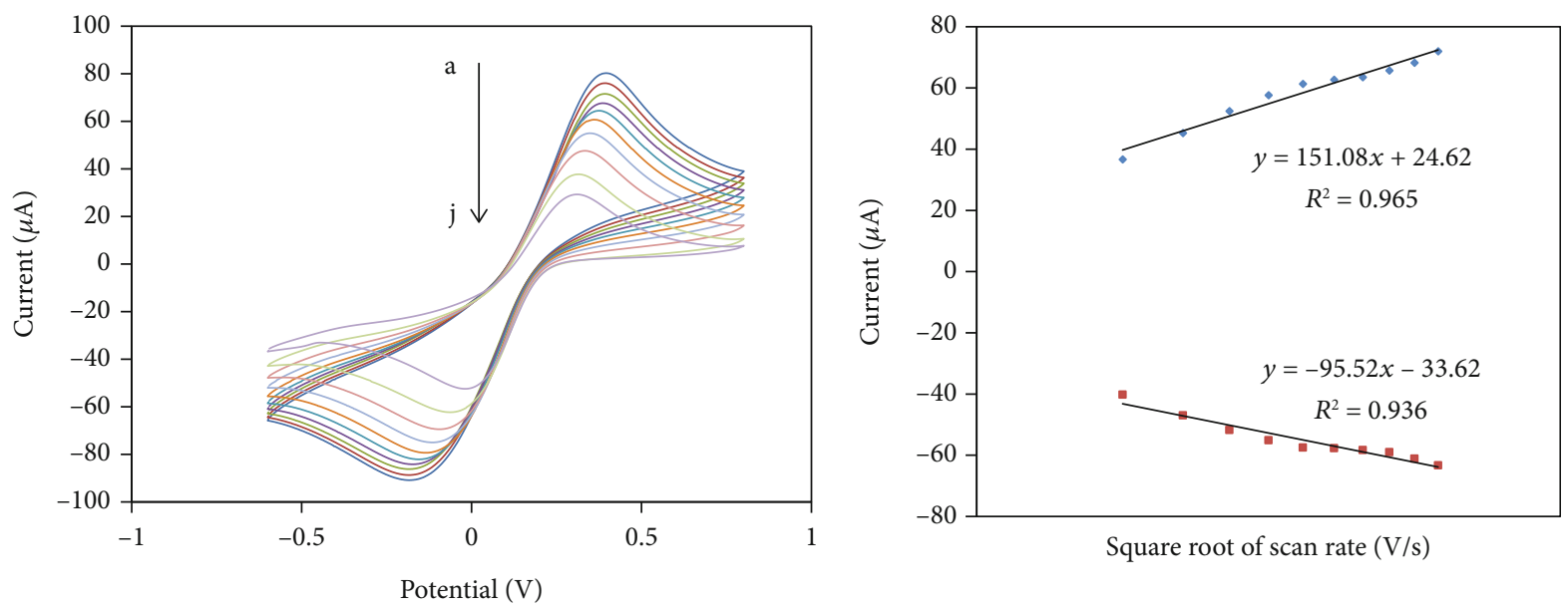

(a)
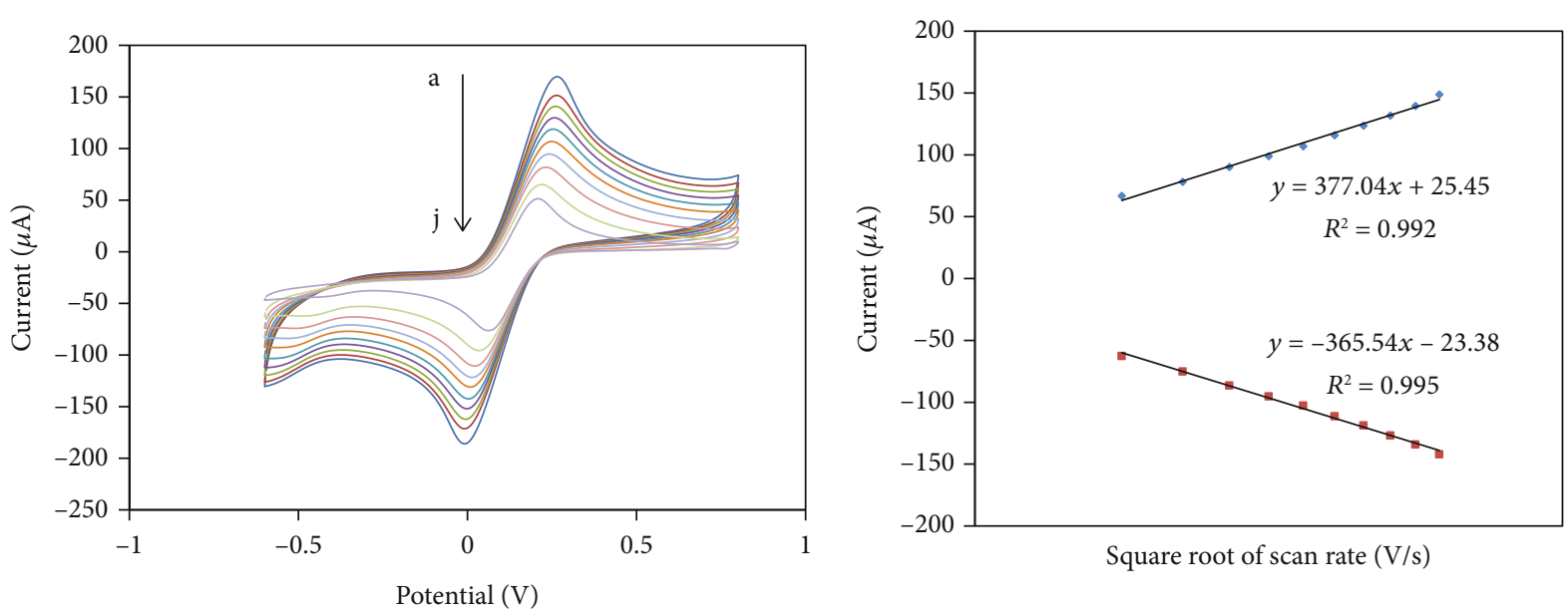

(b)
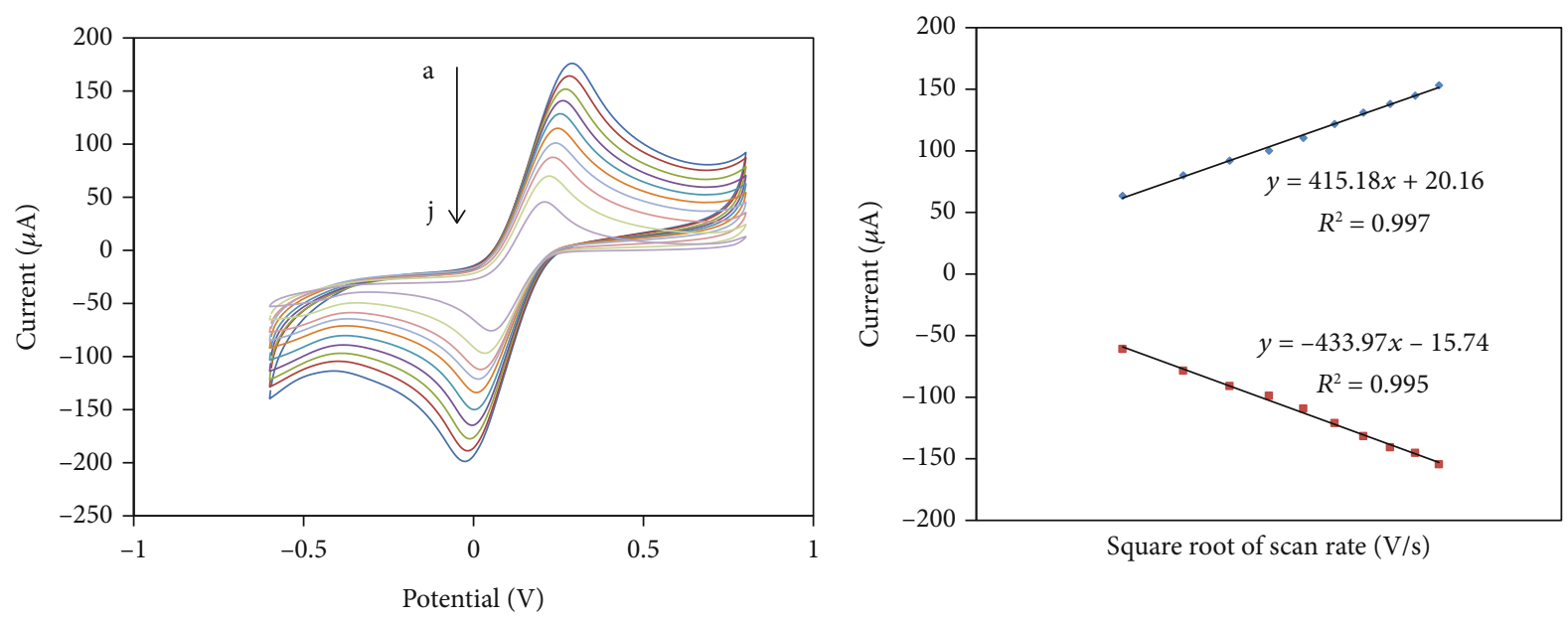

(c)

Figure 4: (a) Cyclic voltammogram of (a) bare, (b) rGO, and (c) rGO/AuNP-modified SPCE in $0.1 \mathrm{M}$ KCl solution containing $5.0 \mathrm{mM}$ [Fe $\left.(\mathrm{CN})_{6}\right]^{3-/ 4-}$ solution. The scan rate was varied from $100 \mathrm{mV} / \mathrm{s}$ to $10 \mathrm{mV} / \mathrm{s}($ a to $\mathrm{j})$. Inset is the linear graph of peak current $\left(I_{\mathrm{p}} / \mu \mathrm{A}\right)$ against the square root of scan rate $\left[v^{1 / 2} /(\mathrm{V} / \mathrm{s})^{1 / 2}\right]$.

and AuNPs were successfully deposited on the surface of electrode and subsequently increased the active surface area of the electrode by approximately two times enhancement compared to bare SPCE because both materials gave good electrical properties. Furthermore, the active surface areas calculated were proportional to the current response 


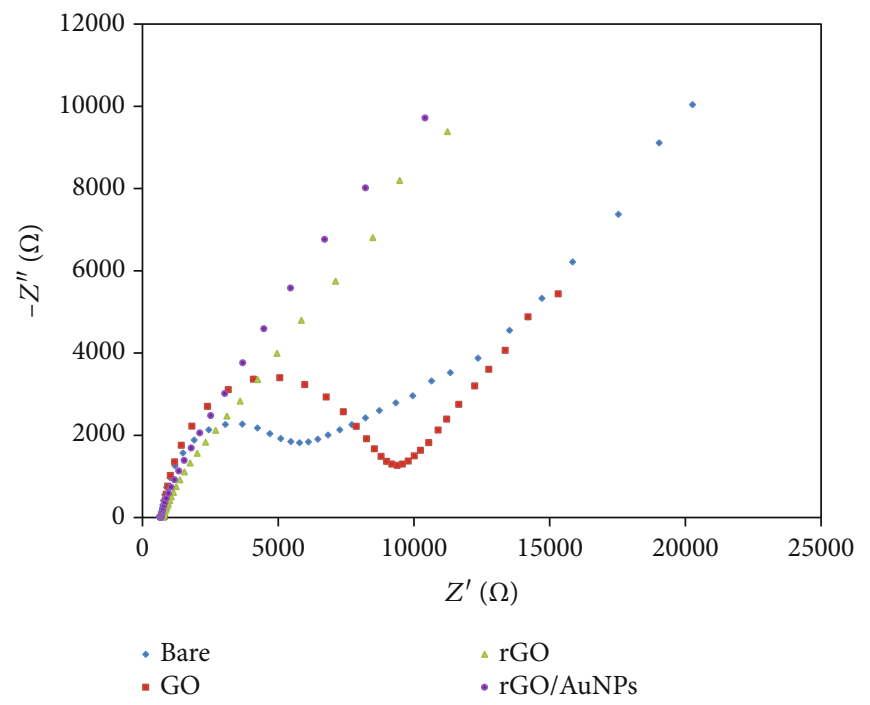

Figure 5: Nyquist plots of bare SPCE, GO, rGO, and rGO/AuNP-modified SPCE in $0.1 \mathrm{M} \mathrm{KCl}$ solution containing $5.0 \mathrm{mM}\left[\mathrm{Fe}(\mathrm{CN})_{6}\right]^{3-/ 4-}$ with frequency $100 \mathrm{kHz}$ and amplitude $0.01 \mathrm{~V}$.

obtained from $\mathrm{CV}$ measurements, which means the redox signal is expected to be higher when the larger surface area is ready to interact with the analytes.

Electrochemical impedance spectroscopy (EIS) is an electrochemical technique which is sensitive to the surface of the electrode and used to investigate the interfacial charge transfer kinetics of the electrodes. A frequency range from $100 \mathrm{kHz}$ to $0.1 \mathrm{~Hz}$ was used for the EIS measurement. The applied potential was set at $225 \mathrm{mV}$ with AC voltage amplitude of $0.01 \mathrm{~V}$. The calculated $R_{\mathrm{ct}}$ values of the modified electrodes showed that the rate of charge transfer of the $\mathrm{rGO} /$ AuNP-modified SPCE $\left(R_{\mathrm{ct}}=650 \Omega\right)$ is the fastest, followed by rGO-modified SPCE $\left(R_{\mathrm{ct}}=699 \Omega\right)$, bare SPCE $\left(R_{\mathrm{ct}}=5.84 \mathrm{k} \Omega\right)$, and the slowest at the GO-modified SPCE $\left(R_{\mathrm{ct}}=8.00 \mathrm{k} \Omega\right)$. As can be seen from Figure 5, when GO was applied onto the electrode surface, the semicircle increased significantly compared to the bare SPCE. GO acted as an insulating layer which increases the resistance of SPCE because of polar and negatively charged oxygen functional groups repelling the access of $\left[\mathrm{Fe}(\mathrm{CN})_{6}\right]^{3-/ 4-}$ ions to the electrode surface which then make the interfacial charge transfer tough between the electrode surface and ferrocyanide ions. After GO film was electrochemically reduced, the semicircle disappeared and gave almost straight lines, indicating that rGO had facilitated the electron transfer between the electroactive species in the electrolyte and the electrode surface owing to the restoration of a graphitic network of $\mathrm{sp}^{2}$ bonds which improved the conductivity of rGO. For rGO/AuNPmodified SPCE, at high frequencies, there was no semicircle observed and the plot showed a more inclined straight line compared with $\mathrm{rGO}$, which meant that the internal resistance of rGO/AuNP composites was smaller due to the good conductivity of AuNPs. AuNPs played a major role to ease and enhance the electron transfer rate at the solution and electrode interface and thus increased the overall conductivity. The outcomes from EIS experiments are consistent with the results obtained from $\mathrm{CV}$ measurements.
3.3. Analytical Performance of $r G O / A u N P$-Modified SPCE towards Palmitic Acid. In this study, 2-methyl-1,4-naphthoquinone (Vitamin $\mathrm{K}_{3}, \mathrm{VK}_{3}$ ) was selected as a quinone reagent due to its stability and solubility in acetonitrile solvent and acted as a redox couple where the reduced species of quinone will interact with hydrogen ions to yield hydroquinone as the product. Lithium perchlorate $\left(\mathrm{LiClO}_{4}\right)$ played a role as the supporting electrolyte to decrease the electrochemical cell resistance. The working solution was prepared by dissolving $\mathrm{VK}_{3}$ and $\mathrm{LiClO}_{4}$ in an acetonitrile/water mixture.

The presence of water in aprotic solvent is a very important factor that should be focused on because water represents hydrogen-bond donor and acceptor. Thus, the use of water needed to be reduced to a minimal amount, yet the mixture (acetonitrile and water) must be able to dissolve all target chemical species especially large amount of $\mathrm{LiClO}_{4}$ which is difficult to dissolve in acetonitrile. Excess water molecules may affect the detection of palmitic acid as water molecules contain hydrogen ions that can interact with the reduced species of quinone in the system. Besides, water also played a role in providing a polar condition to dissolve the proton sources coming from the acids added; hence, the protons would be able to move freely and react with dianion. The experiments were all performed under optimum conditions which the ratios of acetonitrile/water mixture, $\mathrm{VK}_{3}$ concentration, and $\mathrm{LiClO}_{4}$ concentration were $1: 1,4 \mathrm{mM}$, and $3.0 \mathrm{M}$, respectively.

Under optimum conditions, the performance of the developed sensor was first studied using bare electrode. However, from Figure 6(a), only one reduction peak was obtained at $-0.958 \mathrm{~V}$ which was due to reduction of quinone $(\mathrm{Q})$ into semiquinone radical anion $\left(\mathrm{Q}^{--}\right)$. The generation of the second reduction peak which was due to the reduction of semiquinone radical anion into dianion $\left(\mathrm{Q}^{2-}\right)$ was unsuccessful. This is because the conductivity of bare electrode was not strong enough to perform the second reduction process of semiquinone radical anion. The performance of 


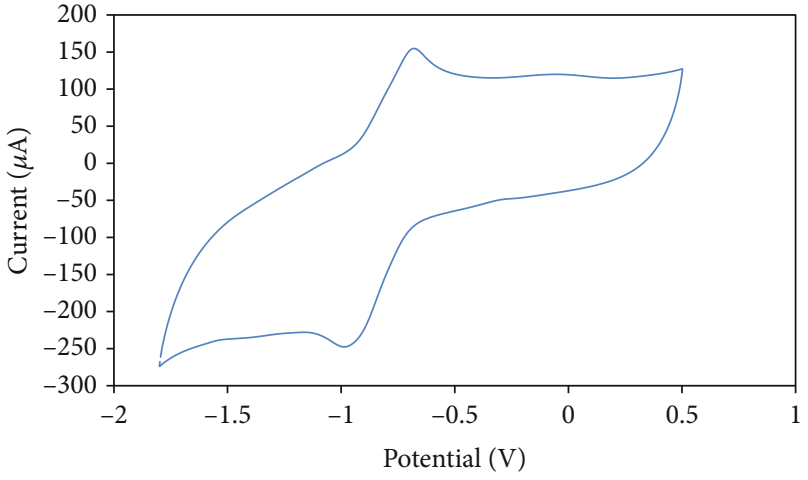

(a)

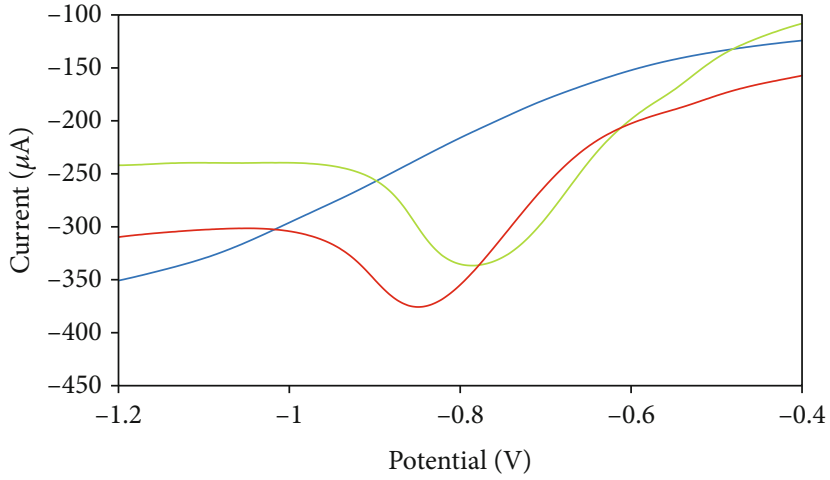

- Bare
rGO
rGO/AuNPs

(b)

Figure 6: (a) Cyclic voltammogram of $\mathrm{VK}_{3}(4 \mathrm{mM})$ in acetonitrile/water mixture in the presence of $\mathrm{LiClO}_{4}(3 \mathrm{mM})$ using bare SPCE; (b) LSV voltammograms of bare SPCE, $\mathrm{rGO}$, and $\mathrm{rGO} / \mathrm{AuNP}$-modified SPCE in acetonitrile/water mixture in the presence of $\mathrm{VK}_{3}, \mathrm{LiClO}_{4}$, and palmitic acid $(0.536 \mathrm{mM})$.

bare electrode towards palmitic acid was carried out. The experiment was done by injecting the palmitic acid with concentration of $0.536 \mathrm{mM}$ into the working solution in the scanning range from $1.5 \mathrm{~V}$ to $-1.5 \mathrm{~V}$ at a scan rate of $50 \mathrm{mV} / \mathrm{s}$ using linear sweep voltammetry (LSV). From Figure 6(b), no peak was obtained because the absence of dianion owing to the fact that only dianion will interact with hydrogen ion from acids to form hydroquinone. Moreover, the comparison between rGO-modified SPCE and $\mathrm{rGO} / \mathrm{AuNP}$-modified SPCE towards palmitic acid at concentration of $0.536 \mathrm{mM}$ was also conducted. As shown in Figure 6(b), rGO/AuNP-modified SPCE showed a better response for the detection of palmitic acid compared to rGO-modified SPCE with a much higher reduction peak current due to the presence of AuNPs which accelerated the electron transfer and further improved the electrochemical performance.

In detail, by using $\mathrm{rGO} / \mathrm{AuNP}$-modified SPCE as shown in Figure 7(a), the first reduction peak was obtained at the potential of approximately $-0.897 \mathrm{~V}$ due to the formation of electrochemically generated semiquinone radical anion from quinone $\left(\mathrm{E}_{1}\right)$ and the second reduction peak was obtained approximately at potential of $-1.251 \mathrm{~V}$ due to the formation of dianion from semiquinone radical anion $\left(\mathrm{E}_{2}\right)$ [30]. Both ions generated were stable and could be successfully detected by cyclic voltammetry where two distinct reduction peaks were observed. Active charged species such as quinones $(\mathrm{Q}$, $\mathrm{Q}^{--}$, and $\mathrm{Q}^{2-}$ ) could dissolve and move freely in the solution due to the high polarity of acetonitrile and ready for the interaction with hydrogen ions released from acid. Electrochemical reduction of quinones was carried out following two consecutive one-electron transfer steps. Compared to semiquinone radical anion, the electrochemical behaviour of dianion is more sensitive to hydrogen ions and can easily form hydrogen bonding interaction and proton transfer. Thus, in the presence of acids, dianion is ready to interact with hydrogen ions or protons from the palmitic acid to form hydroquinone and subsequently gave a reduction peak. The height of the reduction peak obtained was proportional to the concentration of acids added; hence, it could be utilized to detect the palmitic acid content in palm oil [31]. The possible mechanism of reduction of quinone in the solution is summarized as follows:

$$
\begin{aligned}
\mathrm{Q}+\mathrm{e} & \rightleftharpoons \mathrm{Q}^{-} \\
\mathrm{Q}^{--}+\mathrm{e} & \rightleftharpoons \mathrm{Q}^{2-} \\
\mathrm{Q}^{2-}+2 \mathrm{H}^{+} & \rightleftharpoons \mathrm{QH}_{2} \\
\mathrm{Q}+2 \mathrm{H}^{+} 2 \mathrm{e} & \rightleftharpoons \mathrm{QH}_{2}
\end{aligned}
$$

The performance of the developed sensor was then studied with different concentrations of palmitic acid including $0.192 \mathrm{mM}, 0.370 \mathrm{mM}, 0.536 \mathrm{mM}, 0.690 \mathrm{mM}$, and $0.833 \mathrm{mM}$, respectively. The same procedure and measurement with the experiment using bare electrode were used. It can be observed from Figure 7(b) that the reduction peak current responses for both modified electrodes increase proportionally to increase concentration of palmitic acid. This observation could be due to the higher concentration of palmitic acid, which could release more hydrogen ions, and ease the formation of hydrogen bonding, hence increasing the current response [32]. Moreover, the LSV voltammogram showed that the reduction potential shifted slightly towards a negative potential when the concentration of palmitic acid increased. This observation indicated that when quinone was electrochemically reduced to form $\mathrm{Q}^{2-}$, it was ready to interact with hydrogen ions from the acid source to form hydroquinone and the $\mathrm{pH}$ near the electrode surface increases sharply in solution after the hydrogen ions were consumed [33]. When this happened, the reduction potential would decrease rapidly and hence a new peak located at slightly negative potential was formed [34].

From the calibration curve obtained for $\mathrm{rGO} / \mathrm{AuNP}$ modified SPCE as shown in Figure 7(c), it can be noted that as the concentration of palmitic acid increased, the net 


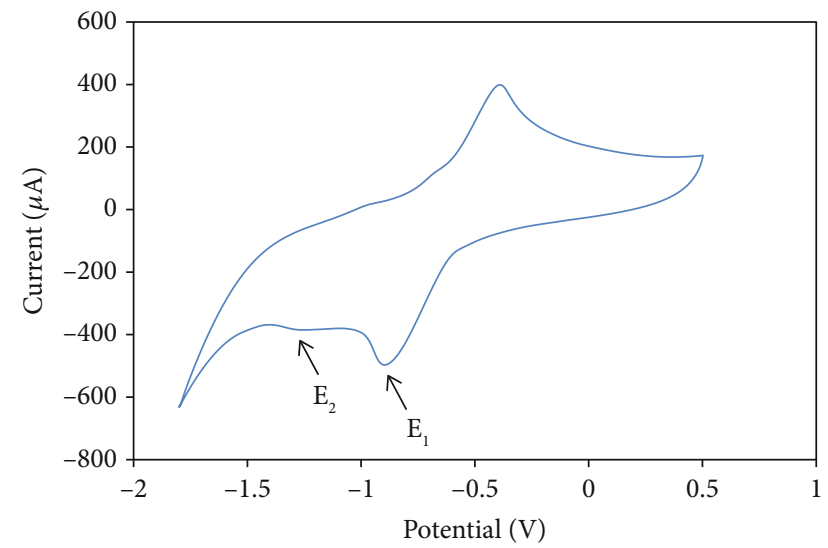

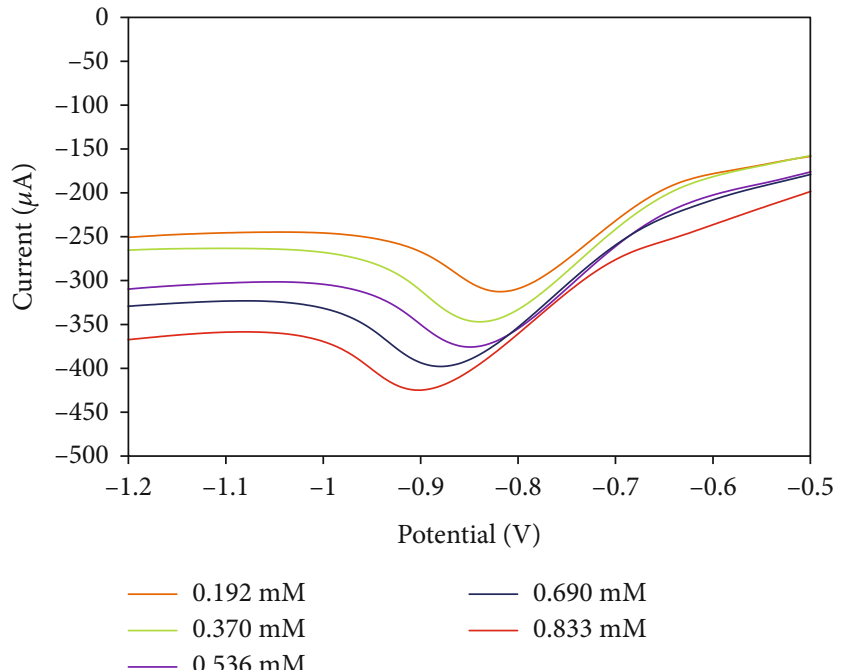

(b)

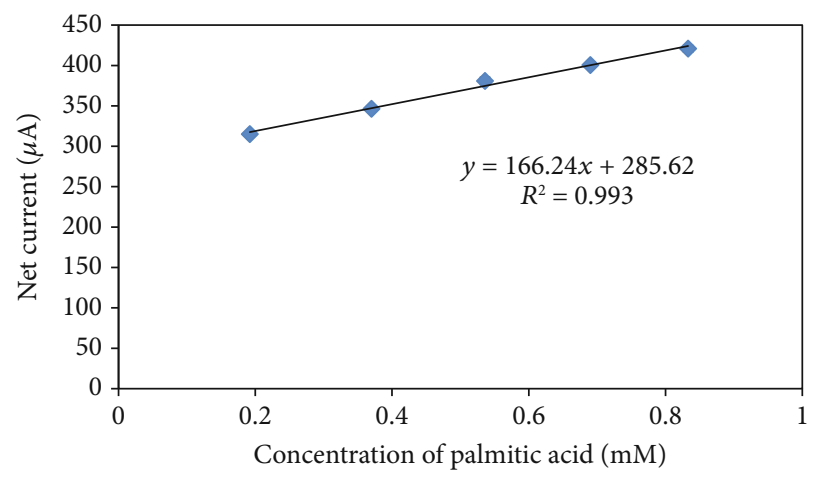

(c)

Figure 7: (a) Cyclic voltammogram of $4.0 \mathrm{mM} \mathrm{VK}_{3}$ in acetonitrile: water $(1: 1, v / v)$ in the presence of $3.0 \mathrm{M} \mathrm{LiClO}_{4}$ using rGO/AuNPmodified SPCE; (b) LSV voltammograms of $\mathrm{rGO} / \mathrm{AuNP}$-modified SPCE in $4.0 \mathrm{mM} \mathrm{VK}_{3}$ consisting of $3.0 \mathrm{M}^{\mathrm{LiClO}} 4$ with various concentrations of palmitic acid: (i) $0.192 \mathrm{mM}$, (ii) $0.370 \mathrm{mM}$, (iii) $0.536 \mathrm{mM}$, (iv) $0.690 \mathrm{mM}$, and (v) $0.833 \mathrm{mM}$; and (c) calibration curve of LSV response of palmitic acid with a concentration range of $0.192-0.833 \mathrm{mM}$ scanning in a positive direction from $1.5 \mathrm{~V}$ to $-1.5 \mathrm{~V}$ at a scan rate of $50 \mathrm{mV} / \mathrm{s},(n=3)$.

current produced also increased. A linear relationship was established with a regression coefficient of $y=166.24 x+$ $285.62, R^{2}=0.993$. The limit of detection (LOD) is calculated to be $0.015 \mathrm{mM}$ based on

$$
\mathrm{LOD}=\frac{3 \sigma}{S}
$$

where $\sigma$ is the standard deviation of the blank and $S$ is the slope of the calibration curve. Thus, rGO/AuNP-modified SPCE showed an excellent response in the detection of palmitic acid with low limit of detection and high sensitivity due to the presence of rGO and AuNPs which aided the electron transfer and further improved the electrochemical performance. The LOD of the developed method was also compared with previously reported work done by Yusof et al. [35] for the determination of palmitic acid using titania nanotube electrode, and the LOD obtained was $1.006 \mathrm{mM}$. Thus, rGO/AuNP-modified SPCE had a better performance towards the detection of palmitic acid with a lower detection limit.

To evaluate the reproducibility study using rGO/AuNPmodified SPCE, five modified electrodes were fabricated by the same procedure and tested in the presence of $0.536 \mathrm{mM}$ palmitic acid using LSV. The current response also remained almost constant, and the obtained relative standard deviation (RSD) value was $0.98 \%$ as shown in Figure $8(\mathrm{a})$. Moreover, the repeatability was also evaluated under the same procedure and the RSD value of $1.67 \%$ was obtained as shown in Figure $8(\mathrm{~b})$. The obtained results suggested that the proposed method for both modified electrodes considerably minimized the sensor-to-sensor deviation and excellent fabrication reproducibility was achieved.

3.4. Applicability of $r G O / A u N P-M o d i f i e d ~ S P C E$ towards Spiked Real Samples. To examine the applicability of the proposed sensor on real sample analysis, the experiment was conducted by spiking a known concentration of stock palmitic acid solution into the stock oil solution (cooking oil). The 


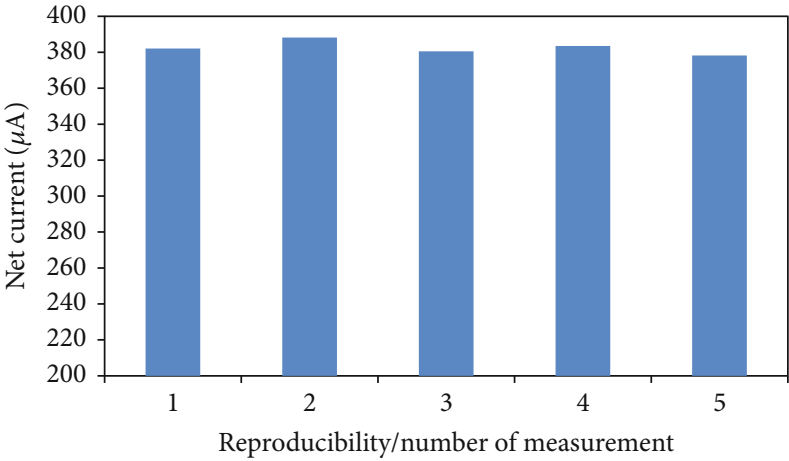

(a)

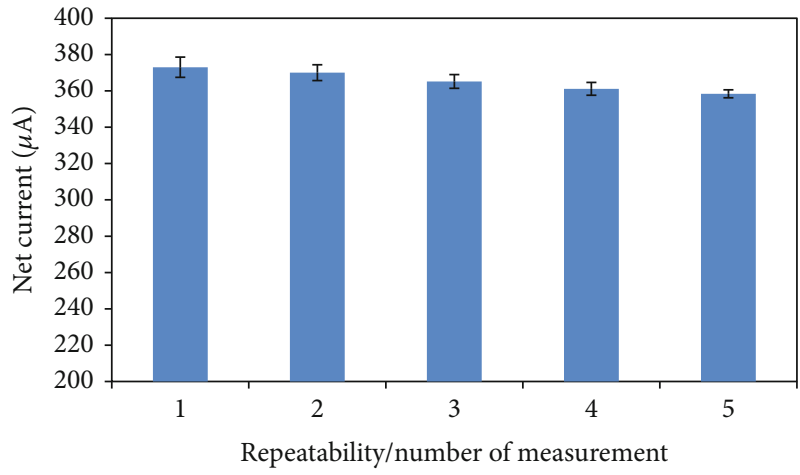

(b)

FIGURE 8: (a) Reproducibility study and (b) repeatability study of rGO/AuNP-modified SPCE in the presence of $0.536 \mathrm{mM}$ palmitic acid in acetonitrile: water $(1: 1, v / v)$ consisting of $4.0 \mathrm{mM} \mathrm{VK} 3$ and $3.0 \mathrm{M} \mathrm{LiClO}_{4}$, scanning from $1.5 \mathrm{~V}$ to $-1.5 \mathrm{~V}$ at a scan rate of $50 \mathrm{mV} / \mathrm{s},(n=3)$.

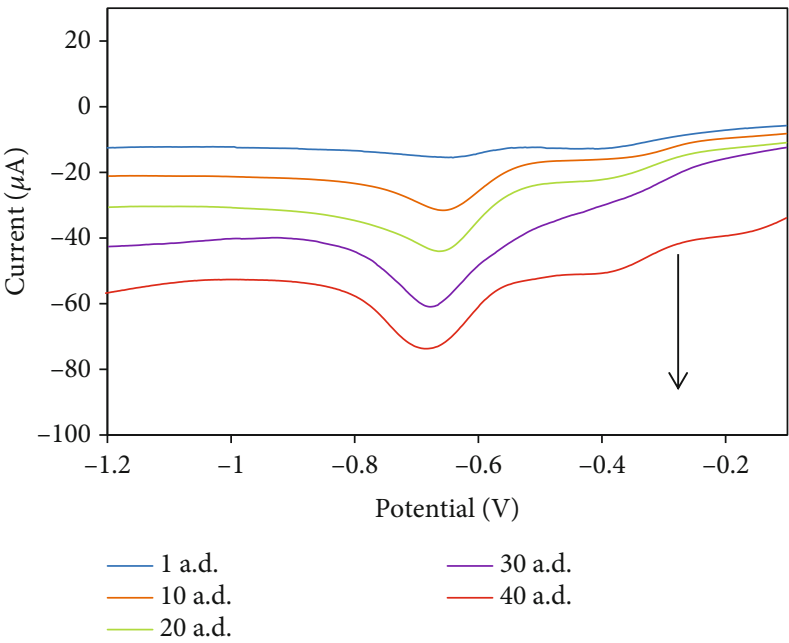

(a)

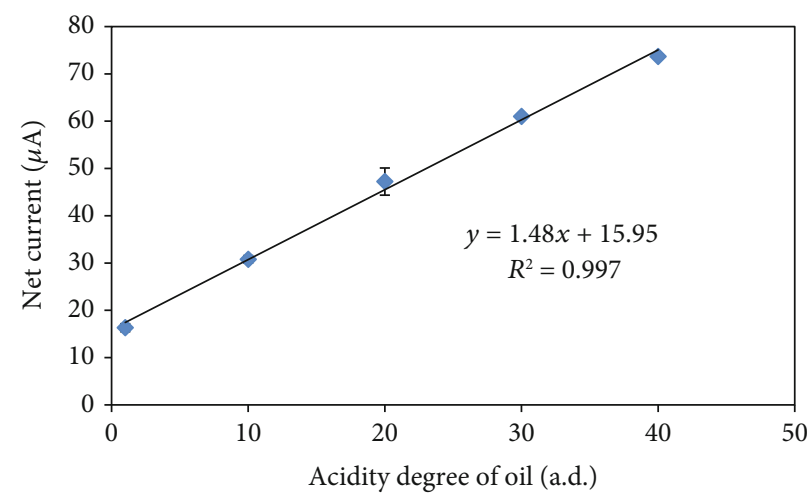

(b)

FIGURE 9: (a) LSV voltammograms of rGO/AuNP-modified SPCE in $4.0 \mathrm{mM} \mathrm{VK}_{3}$ consisting of $3.0 \mathrm{M} \mathrm{LiClO}_{4}$ with various concentrations of palmitic acid: (i) 1 a.d., (ii) 10 a.d., (iii) 20 a.d., (iv) 30 a.d., and (v) 40 a.d.; (b) the calibration curve of LSV response of palmitic acid spiked in cooking oil in the concentration range of $1-40$ a.d. and scanning in a positive direction from $1.5 \mathrm{~V}$ to $-1.5 \mathrm{~V}$ at a scan rate of $50 \mathrm{mV} / \mathrm{s},(n=3)$.

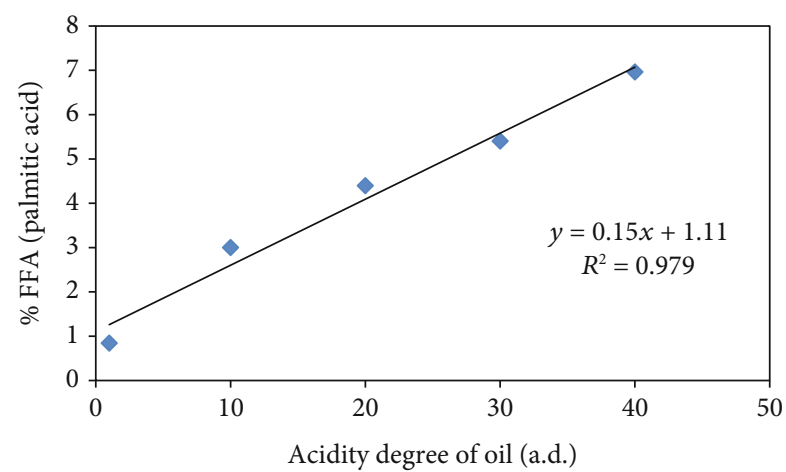

FIGURE 10: Calibration curve of percentage value of palmitic acid by the standard titration method, $(n=3)$.

viscosity of oil may have a slight influence on the electrical conductivity. Theoretically, a decrease in viscosity of oil will result in an increase of mobility of polar molecules and subsequently increase the electrical conductivity [36]. However, in this work, small volume of cooking oil was used; thus, the effect is not significant.

The performance of $\mathrm{rGO} / \mathrm{AuNP}$-modified SPCE towards various concentrations of palmitic acid of 1 a.d. (acidity degree), 10 a.d., 20 a.d., 30 a.d., and 40 a.d. spiked in the stock oil solution was evaluated using the LSV technique. Figure 9(a) illustrates similar observation as previous results (without using the real sample) has been obtained, where the reduction peak current increased linearly with the increasing concentration of palmitic acid. A calibration curve was then plotted as shown in Figure 9(b), and a linear regression coefficient of $1.48 x+15.95, R^{2}=0.997$ for the concentration ranging from 1 to 40 a.d. was obtained.

3.5. Detection of Palmitic Acid with the Standard Titration Method. Figure 10 depicts a linear calibration curve of the standard titration method towards palmitic acid concentrations of 1 a.d., 10 a.d., 20 a.d., 30 a.d., and 40 a.d. spiked in the stock oil solution. A linear relationship between the percentage of free fatty acids (\%FFA) and the acidity degree 


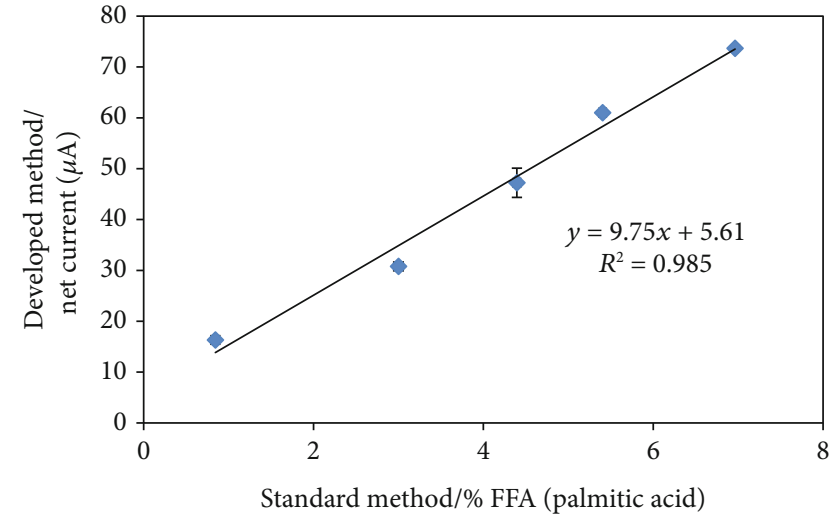

(a)

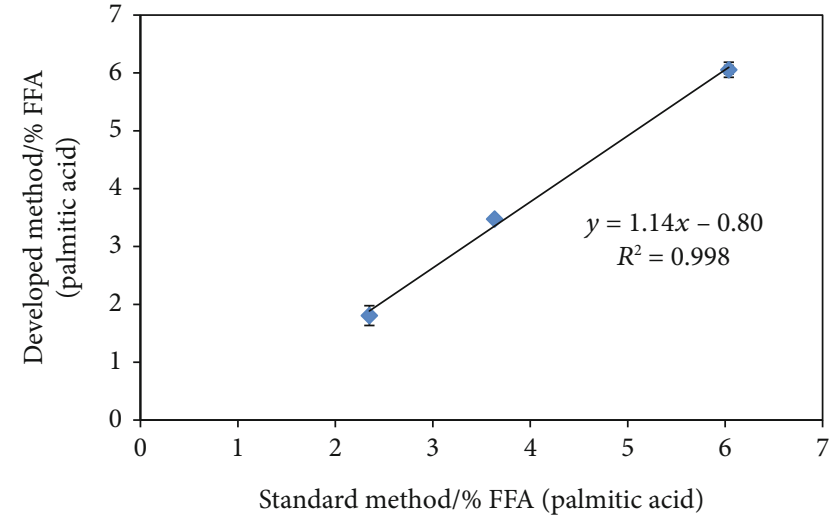

(b)

FIGURE 11: (a) Comparison study between the developed method (electrochemical method) with the standard method (titration method); (b) validation curve of the developed method (electrochemical method) with the standard method (titration method), $(n=3)$.

TABLE 1: Comparison of real sample analysis between the developed methods (electrochemical method) with the standard method (titration method).

\begin{tabular}{lccc}
\hline $\begin{array}{l}\text { Concentration } \\
\text { (a.d.) }\end{array}$ & $\begin{array}{c}\text { The standard } \\
\text { method (\% FFA) } \\
(n=3)\end{array}$ & $\begin{array}{c}\text { The developed } \\
\text { method (\% FFA) } \\
(n=3)\end{array}$ & $\begin{array}{c}\text { Calculated } \\
t \text {-test value }\end{array}$ \\
\hline 5 & $2.35 \pm 0.02$ & $1.80 \pm 0.17$ & 2.74 \\
15 & $3.63 \pm 0.03$ & $3.47 \pm 0.04$ & 3.04 \\
35 & $6.04 \pm 0.04$ & $6.05 \pm 0.13$ & 0.11 \\
\hline
\end{tabular}

Note: $t_{3}=3.18(p=0.05)$.

(a.d.) of palmitic acid with a linear regression coefficient of $0.15 x+1.11, R^{2}=0.979$ was obtained. The volume of $\mathrm{KOH}$ needed to neutralize the acid was then converted into \%FFA using Equation (1). To conclude, the higher the concentration of palmitic acid, the higher the volume of $\mathrm{KOH}$ needed to neutralize the acid, and the higher the percentage of free fatty acids were obtained.

From the developed method (Figure 9(b)), the current response obtained from $\mathrm{rGO} / \mathrm{AuNP}$-modified SPCE was plotted against acidity degree (a.d.). On the other hand, from the standard method (Figure 10), the \%FFA was plotted against acidity degree. Since both of the graphs shared the same unit which is acidity degree, the relationship of the current response from the developed method was then plotted against \%FFA from the standard titration method as shown in Figure 11(a). From the calibration curve obtained, the linear regression coefficient of $9.75 x+5.61, R^{2}=0.985$ was obtained, indicating that both methods were correlated and comparable.

Another three concentrations of palmitic acid that consisted of 5 a.d., 15 a.d., and 35 a.d. were performed for the validation study using both the developed method and the standard method. A validation curve was plotted by converting the current response obtained from LSV into the percentage of FFA using the linear equation from Figure 11(a). Figure 11(b) presents the results of the validation study (both $x$ - and $y$-axis with the same unit which is \%FFA) obtained from the analysis of palmitic acid performed using the developed method by comparing to the result obtained with the standard titration method for concentration of 5 a.d, 15 a.d., and 35 a.d. A good linear correlation was found between these two methods that the fit to the graph had a slope of 1.14 and $R^{2}=0.998$ which indicates good agreement and comparable.

In addition, statistical analysis was also carried out by comparing the two means of the developed sensor and the standard titration method as shown in Table 1. The calculated $t$-values were found to be less than the tabulated value; hence, the difference between the two methods used is insignificant at the $95 \%$ confidence level and the null hypothesis is accepted. The palmitic acid concentrations measured by the rGO/AuNP-modified SPCE sensor were in good agreement and comparable with results from the standard titration method. This highly precise result proved that the proposed sensor can be implemented in the analysis of palmitic acid content in real samples.

\section{Conclusion}

An easy, prompt, and sensitive electrochemical detection of palmitic acid was designed using rGO/AuNP-modified SPCE that was successfully fabricated and characterized in this study. The rGO/AuNP-modified SPCE displayed a better performance, which was attributed to the excellent conductivity and large active surface area of both reduced graphene oxide and gold nanoparticles. The developed sensor showed a linear calibration curve towards palmitic acid in the range of 0.192-0.833 mM with the detection limit of $0.015 \mathrm{mM}$. Moreover, rGO/AuNP-modified SPCE also displayed good repeatability and reproducibility with RSD of $1.67 \%$ and $0.98 \%$, respectively. In addition, the applicability of the developed sensor when tested with spiked real samples was proven and validated with the standard titration method. Cost-effective, green in nature, and coherent methods are among the remarkable features of this designed sensor compared to the traditional methods; hence, it exhibits good potential and could be further developed as an alternative way for the detection of palmitic acid in the future. 


\section{Data Availability}

The data used to support the findings of this study are included within the article.

\section{Conflicts of Interest}

The authors declare that there is no conflict of interests.

\section{Acknowledgments}

The authors would like to thank the Ministry of Higher Education, Institute of Advanced Technology, Universiti Putra Malaysia, and Department of Chemistry, Faculty of Science, University Putra Malaysia, for all facilities and funds provided (GP-IPS/2018/9652900).

\section{References}

[1] C. H. Tan, H. M. Ghazali, A. Kuntom, C. P. Tan, and A. A. Ariffin, "Extraction and physicochemical properties of low free fatty acid crude palm oil," Food Chemistry, vol. 113, no. 2, pp. 645-650, 2009.

[2] A. K. Din, Overview of the Malaysian Oil Palm Industry 2018, 2019, http://palmoilis.mpob.gov.my/V4/wp-content/uploads/ 2020/03/Overview_of_Industry_2018.pdf.

[3] N. H. Azeman, N. A. Yusof, J. Abdullah, R. Yunus, M. N. Hamidon, and R. Hajian, "Study on the spectrophotometric detection of free fatty acids in palm oil utilizing enzymatic reactions," Molecules, vol. 20, no. 7, pp. 12328-12340, 2015.

[4] Y. Tang, R. Huang, C. Liu, S. Yang, Z. Lu, and S. Luo, "Electrochemical detection of 4-nitrophenol based on a glassy carbon electrode modified with a reduced graphene oxide/Au nanoparticle composite," Analytical Methods, vol. 5, no. 20, pp. 5508-5514, 2013.

[5] T. A. Pham, B. C. Choi, K. T. Lim, and Y. T. Jeong, "A simple approach for immobilization of gold nanoparticles on graphene oxide sheets by covalent bonding," Applied Surface Science, vol. 257, no. 8, pp. 3350-3357, 2011.

[6] Z. Zhang, H. Chen, C. Xing et al., "Sodium citrate: a universal reducing agent for reduction/decoration of graphene oxide with au nanoparticles," Nano Research, vol. 4, no. 6, pp. 599$611,2011$.

[7] S. Jampasa, W. Siangproh, K. Duangmal, and O. Chailapakul, "Electrochemically reduced graphene oxide-modified screenprinted carbon electrodes for a simple and highly sensitive electrochemical detection of synthetic colorants in beverages," Talanta, vol. 160, pp. 113-124, 2016.

[8] M. Du, T. Yang, and K. Jiao, "Immobilization-free direct electrochemical detection for DNA specific sequences based on electrochemically converted gold nanoparticles/graphene composite film," Journal of Materials Chemistry, vol. 20, no. 41, pp. 9253-9260, 2010.

[9] M. Song, L. Yu, and Y. Wu, "Simple synthesis and enhanced performance of graphene oxide-gold composites," Journal of Nanomaterials, vol. 2012, Article ID 135138, 5 pages, 2012.

[10] W. Guo, L. Wu, K. Fan et al., "Reduced graphene oxide-gold nanoparticle nanoframework as a highly selective separation material for aflatoxins," Scientific Reports, vol. 7, no. 1, article 14484, 2017.
[11] P. S. Guin, S. Das, and P. C. Mandal, "Electrochemical reduction of quinones in different media: a review," International Journal of Electrochemistry, vol. 2011, Article ID 816202, 22 pages, 2011.

[12] E. da Silva Figueiredo, E. de Castro Vieira, and E. D’Elia, "Comparing a novel voltammetric method with a standardized method for quality control of biodiesel," Journal of Industrial and Engineering Chemistry, vol. 23, pp. 353-361, 2015.

[13] J. Kim, T. D. Chung, and H. Kim, "Determination of biologically active acids based on the electrochemical reduction of quinone in acetonitrile+ water mixed solvent," Journal of Electroanalytical Chemistry, vol. 499, no. 1, pp. 78-84, 2001.

[14] MPOB, A Compendium of Test on Palm Oil Products, Palm Kernel Products, Fatty Acids, Food Related Products and Others, MPOB, Bangi, 2005.

[15] Y. Rao, B. Xiang, X. Zhou, Z. Wang, S. Xie, and J. Xu, "Quantitative and qualitative determination of acid value of peanut oil using near-infrared spectrometry," Journal of Food Engineering, vol. 93, no. 2, pp. 249-252, 2009.

[16] X. Jiang, S. Li, G. Xiang et al., "Determination of the acid values of edible oils via FTIR spectroscopy based on the OH stretching band," Food Chemistry, vol. 2012, pp. 585-589, 2016.

[17] A. S. M. Ali and A. M. Abdurrhman, "Determination of free fatty acids in palm oil samples by non-aqueous flow injection using salicyaldehyde-2, 4-dinitrophenylhydrazone as colorimetric reagent," Chemical and Materials Engineering, vol. 1, no. 3, pp. 96-103, 2013.

[18] S. Y. Toh, K. S. Loh, S. K. Kamarudin, and W. R. W. Daud, "The impact of electrochemical reduction potentials on the electrocatalytic activity of graphene oxide toward the oxygen reduction reaction in an alkaline medium," Electrochimica Acta, vol. 199, pp. 194-203, 2016.

[19] C.-S. Lee, S. Yu, and T. Kim, “One-step electrochemical fabrication of reduced graphene oxide/gold nanoparticles nanocomposite-modified electrode for simultaneous detection of dopamine, ascorbic acid, and uric acid," Nanomaterials, vol. 8, no. 1, p. 17, 2018.

[20] J. M. Jian, Y. Y. Liu, Y. L. Zhang, X. S. Guo, and Q. Cai, "Fast and sensitive detection of $\mathrm{Pb}^{2+}$ in foods using disposable screen-printed electrode modified by reduced graphene oxide," Sensors, vol. 13, no. 10, pp. 13063-13075, 2013.

[21] K. F. Chan, H. N. Lim, N. Shams, S. Jayabal, A. Pandikumar, and N. M. Huang, "Fabrication of graphene/gold-modified screen-printed electrode for detection of carcinoembryonic antigen," Materials Science and Engineering: C, vol. 58, no. 60, pp. 666-674, 2016.

[22] E. Er, H. Çelikkan, N. Erk, and M. L. Aksu, "A new generation electrochemical sensor based on graphene nanosheets/gold nanoparticles/Nafion nanocomposite for determination of silodosin," Electrochimica Acta, vol. 157, pp. 252-257, 2015.

[23] N. Kiroula, J. S. Negi, K. Singh, R. Rawat, and B. Singh, "Preparation and characterization of ganciclovir-loaded glutathione modified gold nanoparticles," Indian Journal of Pharmaceutical Sciences, vol. 78, no. 3, pp. 313-319, 2016.

[24] S. L. Ting, C. X. Guo, K. C. Leong, D. H. Kim, C. M. Li, and P. Chen, "Gold nanoparticles decorated reduced graphene oxide for detecting the presence and cellular release of nitric oxide," Electrochimica Acta, vol. 111, pp. 441-446, 2013.

[25] G. Goncalves, P. A. Marques, C. M. Granadeiro, H. I. Nogueira, M. K. Singh, and J. Gracio, "Surface modification of graphene nanosheets with gold nanoparticles: the role of 
oxygen moieties at graphene surface on gold nucleation and growth," Chemistry of Materials, vol. 21, no. 20, pp. 47964802, 2009.

[26] N. Muhammad, J. Abdullah, Y. Sulaiman, and L. H. Ngee, "Electrochemical determination of 3-nitrophenol with a reduced graphene oxide modified screen printed carbon electrode," Sensor Letters, vol. 15, no. 2, pp. 187-195, 2017.

[27] N. Shams, H. N. Lim, R. Hajian et al., "Electrochemical sensor based on gold nanoparticles/ethylenediamine-reduced graphene oxide for trace determination of fenitrothion in water," RSC Advances, vol. 6, no. 92, pp. 89430-89439, 2016.

[28] X. Wang and X. Zhang, "Electrochemical co-reduction synthesis of graphene/nano-gold composites and its application to electrochemical glucose biosensor," Electrochimica Acta, vol. 112, pp. 774-782, 2013.

[29] J. I. A. Rashid, N. A. Yusof, J. Abdullah, U. Hashim, and R. Hajian, "The utilization of SiNWs/AuNPs-modified indium tin oxide (ITO) in fabrication of electrochemical DNA sensor," Materials Science and Engineering: C, vol. 45, pp. 270-276, 2014.

[30] P. D. Astudillo, D. P. Valencia, M. A. González-Fuentes, B. R. Díaz-Sánchez, C. Frontana, and F. J. González, "Electrochemical and chemical formation of a low-barrier proton transfer complex between the quinone dianion and hydroquinone," Electrochimica Acta, vol. 81, pp. 197-204, 2012.

[31] A. Kotani, F. Kusu, and K. Takamura, "New electrochemical detection method in high-performance liquid chromatography for determining free fatty acids," Analytica Chimica Acta, vol. 465, no. 1-2, pp. 199-206, 2002.

[32] L. Liu, Y. Li, N. Liu, X. Li, and J. Wang, "Differential pulse voltammetric determination of lactic acid in yogurts based on reduction of 1, 4-benzoquinone," Food Analytical Methods, vol. 10, no. 9, pp. 3194-3200, 2017.

[33] S. Cannan, I. D. Macklam, and P. R. Unwin, "Three-dimensional imaging of proton gradients at microelectrode surfaces using confocal laser scanning microscopy," Electrochemistry Communications, vol. 4, no. 11, pp. 886-892, 2002.

[34] J. Wang, H. Wang, S. Guo et al., "The pH changes at the electrode surface caused the new voltammetric waves in PCET reactions," Journal of the Electrochemical Society, vol. 161, no. 9, pp. H443-H446, 2014.

[35] N. H. Yusof, J. Abdullah, N. A. Yusof, and Z. Zainal, "Fabrication of titania nanotube and its application for palmitic acid determination by electrochemical technique," Sensor Letters, vol. 16, no. 10, pp. 729-736, 2018.

[36] D. Kumar, A. Singh, and P. S. Tarsikka, "Interrelationship between viscosity and electrical properties for edible oils," Journal of Food Science and Technology, vol. 50, no. 3, pp. 549-554, 2013. 